Thorax (1952), 7, 178.

\title{
MEDIASTINAL HAEMANGIOMA
}

BY

\author{
O. PERÄSALO \\ From the First Surgical Clinic, University Hospital, Helsinki
}

(RECEIVED FOR PUBLICATION MARCH 5, 1952)

Haemangiomata are relatively frequently observed in various tissues and locations in the body. The mediastinum, however, is an extremely rare site. When in this location, the growth, according to the literature, is frequently malignant, and surgical procedures are not always possible. The case here reported is of interest chiefly for the reason that recovery was good following the surgical removal of a malignant mediastinal haemangioma.

\section{CASE REPORT}

The patient, a 48-year-old woman, an accountant, was admitted to the First Surgical Clinic of the University Hospital on March 28, 1951.

There was no familial history of significant diseases. The patient had been in good health in childhood. Menstruation was regular. At the age of 28 years she had bilateral pulmonary tuberculosis, for which she was treated at a sanatorium, where right artificial pneumothorax was performed for the elimination of an apical cavity. Recovery was found to ke complete five years later. Since then the patient had yearly attended a medical examination for the lungs, but no special findings had been made. The last radiographic examination of the lungs took place about three years previously.

In January, 1951, the patient had influenza. The cough, particularly, was severe, and there was also dyspnoea. Radiographic examination of the lungs revealed a fairly well defined shadow in the inferior and middle fields of the left lung. At the same time, however, she experienced severe pain in the inferior abdominal region, and was admitted to a gynaecological hospital, where total hysterectomy for fibromyoma was performed on February 28,1951 . Upon recovery from this operation she was referred to our clinic for treatment of the tumour on the left side of the mediastinum.

The patient was in a moderately good physical condition and state of nutrition. She was $168 \mathrm{~cm}$. tall and weighed $67 \mathrm{~kg}$. She complained of cough and difficulty in breathing. There was no fever. The right lobe of the thyroid gland was slightly enlarged and nodular, but no symptoms pointing to thyrotoxicosis were present. The lymph nodes were not enlarged. No pathological features were seen in the heart function. Blood pressure was $180 / 100 \mathrm{~mm}$. $\mathrm{Hg}$.

The thorax was symmetrical. Physical examination revealed slight relative dullness anteriorly and pos- teriorly on the left. The respiratory sound was weak over the same area. The vital capacity was $2,100 \mathrm{~mol}$. No tumour cells or tubercle bacilli were found in the sputum. Radiological examination of the lungs showed that the inferior margins expanded. In the inferior field of the left lung, adjoining the heart shadow, there was a shadow about the size of a fist and with a distmet lateral margin in which passive pulsations, but fo active movements, were seen. It was entirely horgogeneous and structureless. The type of passive pulsating movements gave the impression of fluid in the mass (Figs. 1 and 2). Distinctly outlined linear bands were seen in fhe $^{2}$ superior and middle fields of the right lung. No sign activity were seen in any of the lung fields. On the bosis of the radiological finding the case was considered torpbe nearest to a mediastinal cyst (? tumour). The bloogd picture showed a sedimentation rate of $36 \mathrm{~mm}$. inḡan hour, a Sahli value of $82,4.60$ million erythrocytes, a colour index of $0.89,5.800$ leucocytes, and $30 \%$ le phocytes. A differential count gave $63.3 \%$ neutrop $(0.3 \%$ rod cells and $63.0 \%$ segmented cells), $17 \%$ eosinophils, no basophils, and $5.0 \%$ monocytes. The total serum protein was $6.8 \%$ and the serum $\mathrm{NaCl} \$ 00$

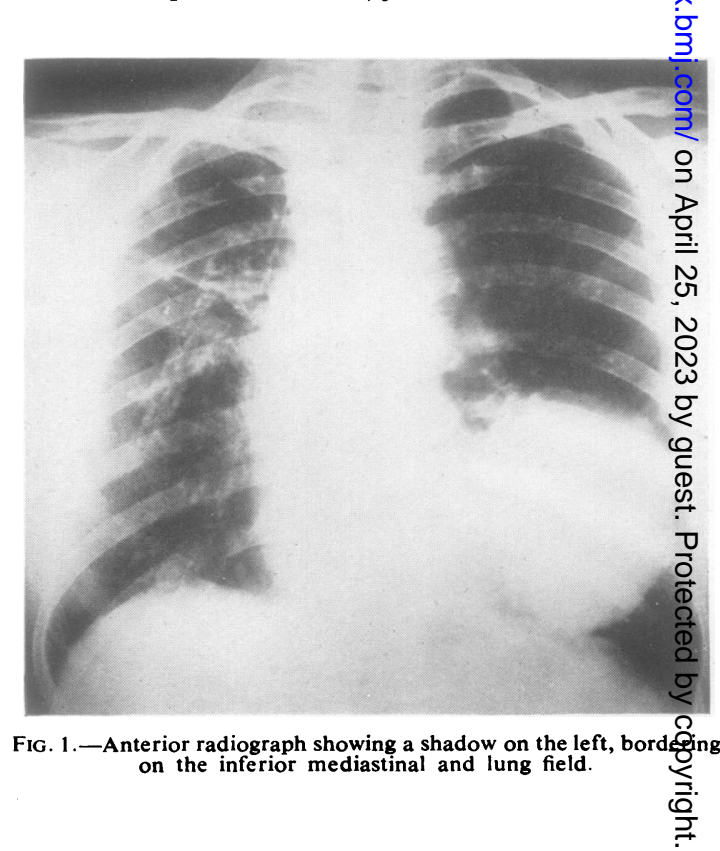




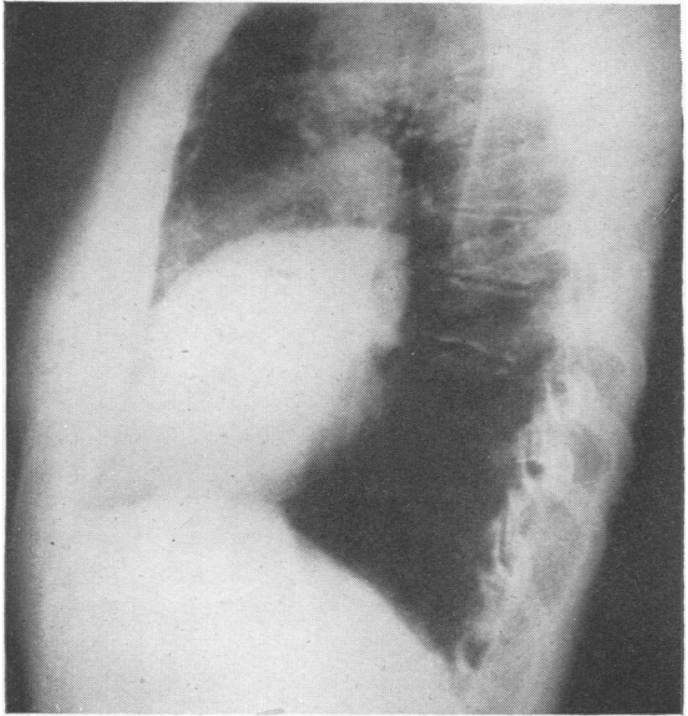

Fig. 2.-Lateral radiograph: the shadow in the inferior lung field is distinct in outline.

mg. per $100 \mathrm{ml}$. No albumin or sugar was present in the urine.

On April 4, 1951, transpleural mediastinotomy and extirpation of the tumour were performed by the writer. The chest was entered by removing the seventh rib subperiosteally. Between the inferior and middle lobes there was a tumour of firm consistency, dark purplish, and with fairly distinct borders. It was firmly adherent to both the superior and the lower lobes. It was mainly attached to the anterior mediastinum and the hilus, to which there were large blood vessels from the capsule. The adhesions were cut by sharp incision. It was then relatively easy to excise the tumour along its capsule after the soft connective tissue stilus was ligated. Sulphapenicillin powder was sprayed in the area of excision, and the thoracic cavity was carefully closed. The pleural cavity was not drained.

The excised tumour was about the size of a man's fist and of firm consistency (Fig. 3). It contained a large amount of yellowish-grey mucoid fluid.

The post-operative reaction was mild. On the first three days the temperature was subfebrile, ranging between 37 and $38^{\circ} \mathrm{C}$. From the fourth day onward the patient was afebrile, and radiological examination showed full expansion of the lungs. The reactive pleurisy was mild, and aspiration was not found necessary. Three weeks after the operation the patient was discharged from the hospital as a convalescent.

Pathological Report.-Histological examination of the tumour showed blood-filled and solid plexa consisting of endothelial cells. Atypical cells were numerous, and a few isolated mitoses were seen. Bands of cells, resembling carcinomatous tissue in structure, formed irregular infiltrations into the connective tissue (Fig. 4). Histological examination revealed a haemangioma, and the cellular structure suggested malignancy.

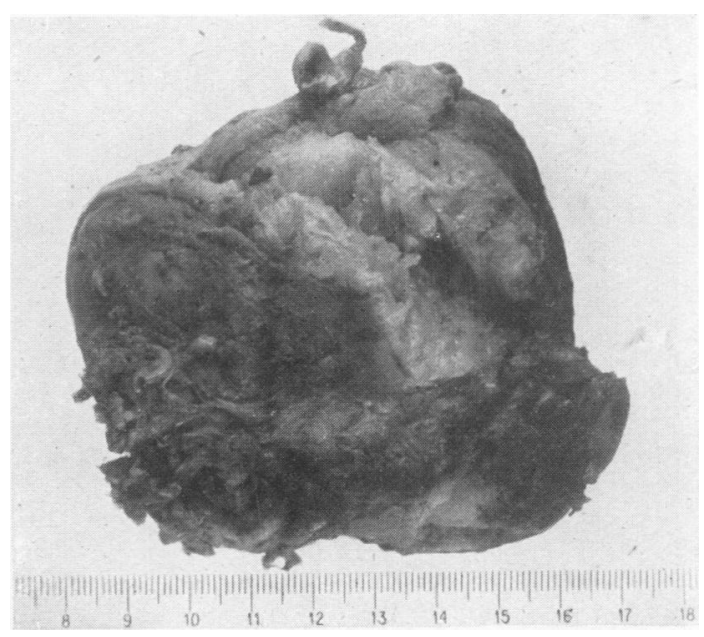

FIG. 3.-Tumour mass removed from the inferior mediastinum.

Follow-up Examination.-At a follow-up examination nearly one year after the operation the patient was in a good general condition. She had gained $4 \mathrm{~kg}$. in weight, and had been occupied in her former work for about a year. No pathological glands were seen. The erythrocyte sedimentation rate was $10 \mathrm{~mm}$. in an hour. Radiological examination of the lungs revealed no changes since the earlier post-operative examinations (Fig. 5).

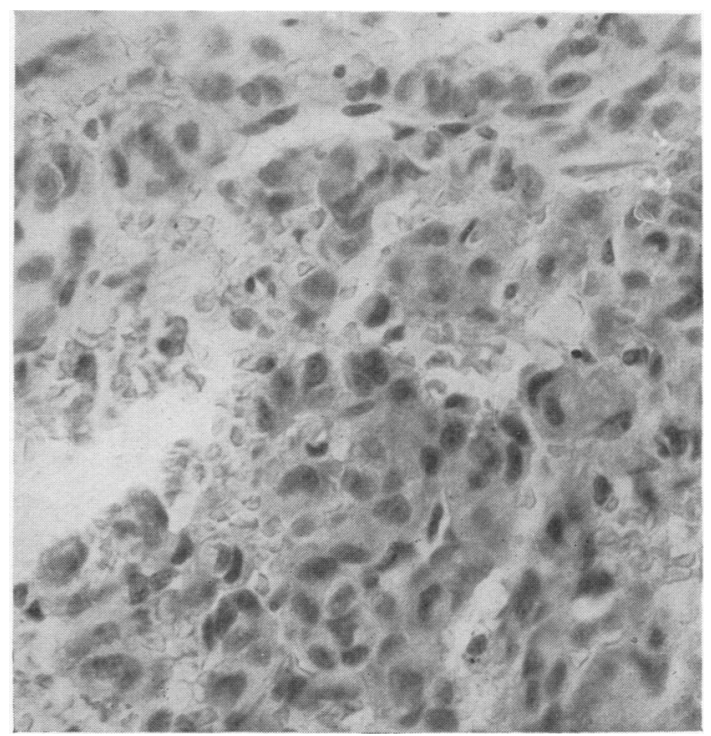

FIG. 4.-Histological section of the tumour mass. Cellular bands infiltrate the connective tissue here and there, in a manner typical of carcinomatous tissue. A haemangioma, in which the cellular structure points to malignancy. $\times 300$ 


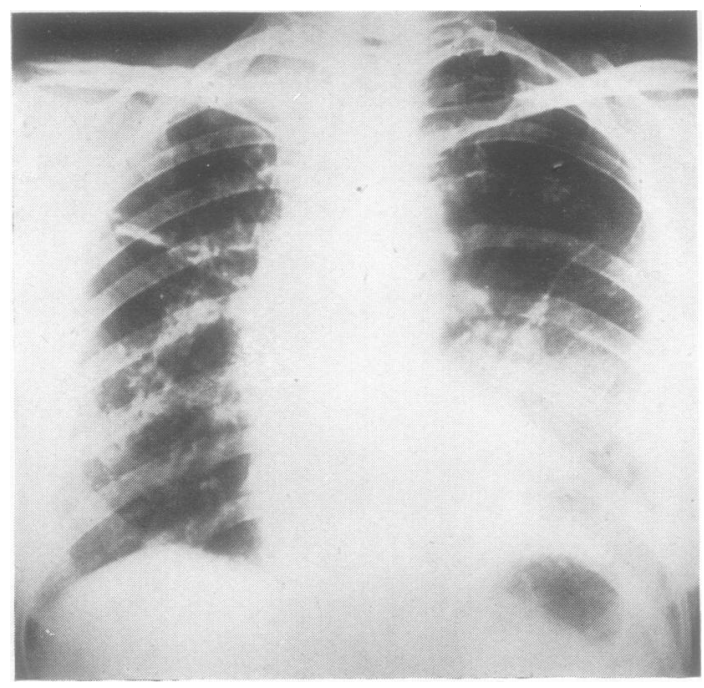

Fig. 5.-Radiograph after operation

\section{Discussion}

Among tumours of the mediastinum the haemangioma is probably one of those most rarely encountered. It is in this respect comparable in the first place to chronic mediastinal granulomata. Comparatively few cases of mediastinal haenangioma have been reported in the literature. Seybold, McDonald, Clagett, and Harrington (1949) published three cases, two of which were malignant haemangio-endothelioma and one a benign haemangioma, collected from 200 cases of mediastinal tumour treated surgically at the Mayo Clinic up to 1947. The same writers described 14 earlier cases. Duvoir, Picot, Pollet, and Gaultier (1939), Thomas and Chesser (1950), and Svanberg have each reported one case. Including the case here described, the number of reported cases of mediastinal haemangioma is thus 21 , that is, 11 malignant and 10 benign cases. The vascular nature of the tumour was not recognized in any of the cases before operation or post-mortem examination.

With reference to localization it seems that the haemangioma has no specific site of predilection $\mathrm{n}$ the mediastinum. It may originate in any mediastinal blood vessel. In Svanberg's case the tumour was found to be closely connected with the second intercostal artery, and in the present case it arose from the anterior mediastinum, mainly from the hilar blood vessels. However, it is frequently very difficult to determine whether a mediastinal haemangioma arises from the mediastinum or the thoracic wall, particularly if the growth is a large one and firmly adherent to the surrounding structures.
It was not possible to make the diagnosis iff a single case before operation or necropsy. In cases a cyst or mediastinal tumour was suspected. As is common in the case of mediastinal tumours in general, the symptoms in these cases vary primarily according to the size and location of the growth. The symptoms usually appear quite late, after the tumour begins to compress nerves, blood vessels, or other organs. No characteristic symptoms have been presented in any reports on mediastimal haemangioma. Fibrillation, bruit, and pulsation may be observed over the area of the tumour, atd these symptoms are probably to some degree significant in these cases. In the case now reported, the type of passive pulsating movement in radiographs gave an impression of the presence of liquid in the tumour mass. With regard to other mediastinal tumours in general and their sympto $\mathrm{p}$ s, reference is made to the numerous earlier studies, among which may here be mentioned those $\mathbb{B}_{\mathrm{y}}$ Burnam (1917), Heuer and Andrus (1940), BlaAes (1941), Alexander (1942), Clagett and Hausmonn (1944), Tiitinen (1949), Nylander and Kyllör xen (1950), Peräsalo (1950), and others.

The usual anterior or lateral radiographic vi\&s reveal only the size and location of the tumo 8 . An angiocardiogram might shed light on the vascularity of the tumour, and for differental diagnosis this method of examination may be $\bar{\delta} f$ considerable significance. The angiocardiogram will also reveal the blood circulation of the thoraeic region and any compression of the blood vessels by the growth. For this reason angiocardiography is indicated in all cases of mediastinal tumour, has been stressed by Svanberg. The angiocarditographic studies made by Steinberg, Dotter, amd Andrus (1950) should particularly be mentioned.

The commonest sites of the haemangioma are he skin and the subcutaneous tissue. Simultaneous occurrence of haemangiomata in the intermal organs, for instance, is not infrequent. The literature contains only one case, reported by Adams and Bloch (1944), of mediastinal haemangio ma with a coexistent solitary cutaneous haemangioma. On the other hand, the patient of Duvoir et al. found to have haemangiomata both in the lumgs and in the abdominal viscera. The coexistence gof pulmonary haemangiomata and arteriovenøus aneurysms and multiple skin and other haemapgiomata appears to be more common, as mentiored by Svanberg (1950).

The haemangioma is a potentially malign $\mathbb{R}_{\mathrm{t}}$ vascular tumour. It contains both capillary a्gd cavernous elements. Although benign by histological structure, it may show infiltrative growith. The growth may be very rapid in children, as in the 
cases reported by Bencini (1936), Döderlein (1938), Bergström (1945), and others. All these children were in good health at birth, but died shortly afterwards, either of haemorrhage or by suffocation due to the growth of the tumour.

The pre-operative diagnosis of mediastinal hacmangioma is difficult. These tumours may become large and produce severe symptoms, as do other neoplasms of the mediastinum. It is generally considered that surgical removal is indicated if the mediastinal tumour is unilateral. An exception are those cases where a known systemic disease or a mediastinal tuberculoma in an active stage is present. It seems that prognosis is good after operation for a distinctly encapsulated benign mediastinal haemangioma. However, malignancy may frequently develop in a mediastinal haemangioma, and growth will then be rapid and infiltrative. In the writer's case the malignant haemangioma had developed in less than three years. Its histological features indicated that the malignant process was recent and that infiltrative growth was early. For successful surgical intervention, an early diagnosis of a mediastinal haemangioma is of the utmost importance.

Thoracotomy was performed in seven of the published cases of mediastinal haemangioma. In four of these it was possible totally to remove the tumour, i.e. in one case of Seybold et al. (1949), and in those of Watson and Diamond (1947), Thomas and Chesser (1950), and of the present writer. In the case of Adams and Bloch (1944) the tumour could not be completely removed. Recovery was good in all of these cases; but, no information is available on the outcome of the operation in the case of Watson and Diamond. The haemangioma was inoperable in the two cases reported by Duvoir $e t$ al. and Svanberg. In the former case, the patient died of pneumonia five years later, and radiographs revealed further growth of the tumour. In the latter case, radiotherapy was beneficial. The tumour was small, and radiography of the lungs five years later showed complete disappearance of the growth. The patient was a child 4 years of age. In two of the cases in which total or partial removal of the tumour was possible, i.e. those of Adams and Bloch and of the present writer, the haemangioma was malignant.

Radiotherapy may be worth trying, at least in inoperable cases. The response may be very satisfactory, particularly with young persons, as for instance in Svanberg's cases. The use of radiotherapy in the treatment of cutaneous haemangioma is well known, although it is not always to be preferred to surgical treatment; this is recommended by, among others, Blechschmidt (1951). It is possible that the sensitivity of the mediastinal haemangioma to irradiation is greater with children, as is the case with haemangiomata of the skin.

In the case here described, where radical extirpation of the haemangioma was possible, no irradiation therapy was given, chiefly because there was a history of pulmonary tuberculosis and radiological examination showed evidence of mild activity. However, nothing pointing to a relapse and no glandular metastases were seen at the follow-up examination nearly one year later. Adams and Bloch's patient also had a malignant haemangioma, which could not be completely removed, but the operation appears to have been successful, since the patient was alive and in good health four years later. It may therefore be presumed that cases where the haemangioma is not completely encapsulated and radical removal is not possible need not be hopeless. However, where histological examination reveals malignancy, the prognosis should always be made with certain reservations, for it cannot be judged on the basis of other individual cases.

\section{SUMMARY}

A case of mediastinal haemangioma in which the tumour was encapsulated and localized on the left side is reported. Complete removal was possible at operation. The histological features pointed to malignancy. Post-operative recovery was good, and a follow-up examination nearly one year later show $d$ that the patient was entirely asymptomatic.

Earlier reports of mediastinal haemangioma are discussed, with special attention to diagnosis and treatment. Where surgical removal of the tumour is not possible, radiotherapy should be atte mpted, particularly if the patient is a child.

REFERENCES

Adams, W. E., and Bloch, R. G. (1944). Arch. Surg., Chicago, 48, 126.

Alexander, J. (1942). J. Amer. med. Ass., 119, 395.

Bencini, B. (1936). Cuore e Circol., 20, 645.

Bergströ̀m, V. W. (1945). N.Y. St. J. Med., 45, 1867.

Blades, B. (1941). Amer. J. Surg., 54, 139.

Blades, B. (1941). Amer. J. Surg., 54, 139.

Blechschmidt, W. (1951). Med. Welt, $20,1358$.
Burnam, C. F. (1917). J. Amer. med Ass., 69, 989.

Clagett, O. T., and Hausmann, P. F. (1944). J. thorac. Surg., 13, 6. Duvoir, M., Picot, G., Pollet, L., and Gaultier, M. (1939). Bull. Soc. méd. Hop. Paris, 55, 596.

Döderlein, F. (1938). Zbl. allg. Path. path. Anat., 71, 193

Heuer, G. J., and Andrus, W. DeWitt (1940). Amer. J. Surg., 50, 146.

Nylander, P. E. A., and Kyllönen, K. E. J. (1950). Ann. Chir. Gynaec. Fenn., 39, 200.

Peräsalo, O. (1950). Ibid., 39, 213.

Seybold, W. D., McDonald, J. R., Clagett, O. T., and Harrington, S. W. (1949). J. thorac. Surg., 18, 503.

Steinberg, I., Dotter, C. T., and Andrus, W. DeWitt (1950). Surg. Gynec. Obstet., 90,45 .

Svanberg, L. (1950). Svenska LäkT., 47, 1511.

Tiiting Personal communication.

Tiitinen, E. (1949). Ann. Chir. Gynaec. Fenn., 38, 185.

Thomas, N. K., and Chesser, I. M. (1950). J. thorac. Surg., 20, 321.

Watson, W. L., and Diamond, H. D. (1947). Ibid., 16, 1. 